\title{
Effect of thermal processing on total phenolic content and antioxidant activity of Mentha leaves
}

\author{
SNIGDHA CHAWLA ${ }^{1}$ AND MONIKA THAKUR ${ }^{2}$
}

\author{
${ }^{1}$ School of Biotechnology, Gautam Buddha University, GREATER NOIDA (U.P.) INDIA \\ ${ }^{2}$ Amity Institute of Food Technology, Amity University, NOIDA (U.P.) INDIA \\ Email : mthakur1@amity.edu; monika.harsh05@gmail.com
}

\begin{abstract}
Mint is a promising health promoting herb, which is not only used for flavour and aroma, but also has many potential health benefits. Effect of refrigeration as well as thermal processing methods (blanching and boiling) on potential health benefits of mint was studied by determination of antioxidant activity and content of total phenolic substances in ethanolic extracts of mint leaves. The leaves were subjected to blanching $\left(80^{\circ} \mathrm{C}\right)$, boiling $\left(100^{\circ}\right)$ as well as storage at refrigerated temperature $\left(4^{\circ} \mathrm{C}\right)$. A qualitative phytochemical screening was performed. The ethanolic extracts were analyzed for total phenolic content using Folin-Ciocalteau assay and free radical scavenging activity using 2,2diphenyl-1-picrylhydrazyl (DPPH) radicals. Thermal treatment caused significant decrease in antioxidant activity as well as total phenolic content of mint leaves. Total phenolic content in fresh sample was $115.81 \mathrm{mg} \mathrm{GAE} / \mathrm{g}$, which decreased to $3.59 \mathrm{mg}$ GAE/g when leaves were subjected to $100^{\circ} \mathrm{C}$. Antioxidant activity reduced from 77.9 per cent in fresh leaves to 48.7 per cent in boiled leaves. The study indicated that polyphenols and phenolic acids, responsible for antioxidant action of mint, were degraded by heat, thereby reducing the medicinal value of herb. The study thus, suggests the consumption of fresh mint leaves to obtain the maximum health benefits.
\end{abstract}

Key words : Mentha, Bioactive components, Phytochemical screening, Antioxidant potential, Total phenolic content

How to cite this paper : Chawla, Snigdha and Thakur, Monika (2014). Effect of thermal processing on total phenolic content and antioxidant activity of Mentha leaves. Asian J. Bio. Sci., 9 (2) : 200-203. 